\title{
Exploring the Relationship between School Growth Mindset and Organizational Learning Variables: Implications for Multicultural Education
}

\author{
Janet Hanson (Corresponding author) \\ Department of Educational Leadership, Montana State University (MSU) \\ 457 Reid Hall, Bozeman, Montana, USA \\ $\&$ \\ Educational Leadership Department, Azusa Pacific University \\ P.O. Box 7000, Rm 137, Azusa, CA 91702-7000, USA \\ Tel: 1-(626)-815-5375 E-mail: jhason@apu.edu
}

\begin{abstract}
Arthur Bangert
Department of Educational Leadership, Montana State University (MSU)

115 Reid Hall, Bozeman, Montana, USA
\end{abstract}

Tel: 1-(406)-994-7424Ｅ-mail: abangert@montana.edu

\begin{abstract}
William Ruff
Department of Educational Leadership, Montana State University (MSU)

457 Reid Hall, Bozeman, Montana, USA
\end{abstract}

Tel: 1-(406)-994-4182Ｅ-mail: wruff@montana.edu

Received: September 23, 2016 Accepted: October 20, 2016

Published: November 3, 2016

doi:10.5296/jei.v2i2.10075 URL: http://dx.doi.org/10.5296/jei.v2i2.10075 


\section{Abstract}

According to school growth mindset theory a school's organizational structure influences teachers' beliefs in their collective ability to help all students grow and learn; including those from diverse cultural, religious, identity, and socioeconomic demographics. The implicit theory of growth mindset has been quantified for a school's culture on the What's My School Mindset scale. This exploratory study was an initial effort to examine the content validity of the school growth mindset construct using SPSS to perform correlation analysis with multicultural relevant, organizational learning variables from the literature that were shown to explain improved school outcomes. Regression analysis tested the hypothesis that the independent variables would explain variations in a school's growth mindset mean. Data was collected from a random stratified sample of middle and high school teachers $(n=64)$ and administrators $(n=5)$ in a large northwestern state. Responses were collected on the 19-question Likert-style WMSM survey. The overarching research question was, Is there a relationship between principal openness to change, faculty openness to change, work locus of control, and a school growth mindset? The results revealed organizational learning variables significantly correlated with a growth mindset culture and explained significant variations in the WMSM mean. The results have positive implications for providing school administrators with a way to measure their school's culture and to provide feedback to teachers that can challenge their beliefs and inform improvements in culturally responsive teaching practices.

Keywords: Implicit theories, School culture, Multicultural, Survey, Organizational learning

\section{Implicit Theories and Improved School Performance}

Research on implicit theories of mind are being reported in current literature showing influences on teacher and student psychosocial factors contributing to improved school and student performance (Farrington et al., 2012). Thornton and McEntee (1995) described mindsets as a factor providing "insights into the social phenomenon of learning, the reciprocal exchange of ideas and information" that occurs in the school environment and are used to co-construct knowledge bases (p. 251). A school's context has been shown to strongly influence individuals' implicit theories and reciprocally to influence the school organization. How one perceives their world has also been linked to one's culture of origin (Hong, Benet-Martinez, Chiu, \& Morris, 2003; Nisbett \& Miyamoto, 2005). In the current context of diverse student populations, the study of implicit theories and their influence on multicultural education warrants exploration for identifying variables useful to support improved school cultures and culturally responsive teaching practices. A school's culture, including variables contributing to equitable practices, has been shown to directly explain improvements in school outcomes (Tarter \& Hoy, 2004).

Multiculturalism in schools is a perceptual lens that focuses the mind on accepting diverse ways of behaving as legitimate (King \& Kitchener, 1994; King \& Shuford, 1996). Multiculturalism is shaped by social experiences, conditioning, and language. A multicultural environment requires cognitively complex reflexive thinking, is open to differences, and uses reflection and action as the basis for change that "facilitates social justice in a multicultural, democratic society" (Thornton \& McEntee, 1995, pp. 250-254). For example, one outcome 
from increased cultural responsiveness in schools was overcoming implicit biases and stereotype threat (Dweck, 2008, 2010; Good, Dweck, \& Rattan, 2008; Mangels, Good, Whiteman, Maniscalco, \& Dweck, 2012; Smith, 2015). Cultural responsiveness does not arise automatically. It takes hard work to develop a change in one's beliefs (Dweck, 2011). At her seminar titled, "The Diversity Imperative for Excellence in Higher Education: Building Capacity in a Pluralistic Society," D. Smith (personal communication, July 18, 2015) explained there are few examples of pluralistic societies that work. Types of new learning that facilitate reaching the goal of culturally responsive teaching include learning about diversity, using self-reflection of how one behaves in a complex sociocultural environment, recognizing the differences in cognitive filters between teacher and student, and participating in challenging conversations about social justice and educational equity for diverse students (Gay, 2010; Negari \& Donyadary, 2013). Vygotsky (1926; 1962) and Bandura (2001) both demonstrated the important role of social interaction, modeling, and dialogue in developing cognitive change that resulted in meaningful learning.

\subsection{Goal of the Study}

This study tested the relationship between selected organizational learning variables and a school's growth mindset. The independent variables of principal openness to change, faculty openness to change, and work locus of control have been shown to explain improvements in school outcomes, and compared favorably to variables of culturally responsive teaching in schools (Tarter \& Hoy, 2004; Gay, 2010). The rationale for the study was that if organizational learning variables positively correlate with teacher perceptions of their school's growth mindset culture then these variables, if malleable to administrator influence, may be used in school and teacher interventions to improve outcomes for all students (Walton, 2014). The overarching question for this study was, "Is there a relationship between principal openness to change, faculty openness to change, work locus of control and school growth mindset?"

\subsection{Definitions}

Social Cognitive Theory (SCT): provides a framework to explain the way individuals learn and behave through a triad of reciprocal influences from observing the behavior of others, influences in their social environment, and their own internal factors (Bandura, 2001).

Collective Efficacy: is a concept comprised of two constructs: 1) the faculty perceptions of their group competence in teaching methods, skills, training, and expertise; and 2) task analysis, influenced by the abilities and motivation of students, and the support provided by the various contexts of home, school, and community (Goddard, 2002, p. 100).

Principal openness to change: is a measure of the willingness, speed, responsiveness, and commitment with which the principal acts to support change in the school (Smith \& Hoy, 2005).

Faculty openness to change: The receptiveness and willingness of teachers and faculty as a whole to accept change in the school, to welcome new ideas from parents, and embrace substantial changes in rules and procedures without opposition (Smith \& Hoy, 2005). 
Locus of control: "a generalized expectancy that [one's] rewards, reinforcements, or outcomes in life are controlled either by one's own actions (internality) or by other forces (externality) (Spector, 1988, p. 335). Locus of control is domain specific and in this study the locus of control variable used was in the domain of teacher work in the school.

School Growth Mindset: a culture with a "common vision, sharing knowledge, support, and resources" (Blackwell, 2012, para. 6-10). The school growth mindset is a unidimensional construct with three subfactors: collaborative planning, shared leadership, and open communication \& support (Hanson, Bangert, \& Ruff, 2016).

The following section provides a discussion on social cognitive and organizational learning theories, enabling school structures, and open systems variables as a means to evaluate the content validity of the school growth mindset culture purported to be operationalized on the WMSM scale.

\section{Literature Review}

Organizational variables were found in a review of relevant literature that contribute to a multicultural view and culturally responsive teaching in schools including; a disposition of openness to change, a willingness to participate in self-awareness through reflection, and a sense of autonomy over one's learning activities (Gay, 2010; Walker-Dalhouse \& Dalhouse, 2006). These variables compared favorably to the five key features included in the description of a growth mindset school culture; shared leadership, open communication, peer support, goal setting, professional collaboration, and a belief all teachers can help all students grow and learn (Blackwell, 2012).

\subsection{Meaningful Learning}

Positive relationships contribute to the negotiation of meanings that must occur between the teacher and the students in order to develop meaningful learning (Novak, 2011, p. 2). Meaningful learning occurs through the process of challenging assumptions. When assumptions are challenged, an individual with a disposition of openness to change begins the process of comparing one's new experiences with prior learning. If a significant difference exists, the individual deconstructs some part of prior beliefs. Through the process of reconstruction the individual makes corrections of erroneous or inaccurate cognitive maps of how he views his world (Novak, 2002, 2011; Novak \& Gowin, 1984). Kang, Scharmann, \& Noh (2004) wrote, "motivational constructs, such as mastery goal orientation, adoption of a constructivist belief about learning, higher levels of personal interest, self-efficacy, and personal control, should be potential mediators of the process of conceptual change" (p. 91). The development of meaningful learning in students is a sound dependent measure to evaluate the quality of the school context (Schunk, 2012).

Bowers and Flinders (1990) in Gay wrote, "[B]ehavior is largely a matter of communicating in culturally prescribed ways" (p. 71). A teacher's cultural responsiveness is demonstrated in his expectations of the student and in his instructional behaviors toward the student.

Professional development is indicated when organizational cultures and teacher beliefs are 
lacking that they can help all students in their school learn and grow. Caring about their students is one aspect of a faculty's caring behaviors. A second, and more complex, is understanding how to care for culturally diverse students (J. Carjuzaa, personal communication, March 15, 2015). Using the growth school mindset survey teachers can quantify their beliefs about themselves and their school culture (espoused theories) and compare the results to their actual behaviors, or theories-in-use (Argyris \& Schon, 1996; Blackwell, 2012; Mindset Works, Inc., 2015a-2015c; Ruff, 2002). The school faculty can explore possible reasons and challenge themselves to learn more if culturally responsive behaviors are not present. Engaging in difficult dialogues is one of the essential practices for changing institutional practices and building institutional capacity in excellence toward diversity (D. Smith, personal communication, July 18, 2015).

\subsection{Growth School Mindset Theory}

The concept of learner agency, or control over one's environment, was central to the psychological and socio-cognitive processing model of a growth mindset. Growth mindset theory is situated in the literature of the social cognitive model of motivation and learning and describes the learner's need for a belief in "establishing and maintaining ... [a] subjective sense of prediction and control" over one's experience in the world (Plaks, Grant, \& Dweck, 2005 , p. 245). Implicit theories of fixed or incremental mindset explained increased self-regulatory processes of goal setting that were similar to constructs of human agency (Baumeister, Masicampo, \& Vohs, 2011; Hong, Morris, Chiu, \& Benet-Martinez, 2000). The social context strongly influences learner agency (Blackwell, 2012; Spector, 1988; Wang, Bowling, \& Eschleman, 2010). The social group has a powerful influence on whether the learner experiences internal or external locus of control as described in Bandura's (2001) social cognitive theory.

Researchers are currently exploring the usefulness of psychosocial supports within the school environment that will produce learner choice to engage new knowledge. These supports include goal alignment, feedback, resources, and skill development (Bandura, 1986, 2001; Dweck, 1986; Dweck \& Leggett, 1988; Martin, 1979; Novak \& Gowin, 1984; Rottschaefer \& Knowlton, 1979; Zimmerman, 1989). These psychosocial supports are consistent with features of a school growth mindset culture (Blackwell, 2012; Mindset Works, Inc., 2015a-2015c). These are also factors used in interventions to develop effective school cultures that support all students toward developing meaningful learning outcomes (Ponton \& Rhea, 2006; Walton, 2014).

\subsubsection{Goal Alignment}

The mindset of the organization has consequences for the behaviors and perceptions of the group and individuals in the group. Learning organization theory suggests an organization acts as a single entity with its own goals, values, and organizational behaviors (Hoy \& Sweetland, 2001; Tarter \& Hoy, 2004). Bandura (2001) explained that the wellbeing of the individual within an organization depends on the alignment of the individuals' goals with the system's goals. Changes in school climate were shown to leverage improvements in school outcomes. These changes included individual agency, collaborative decision-making, 
recognition of the individual nature of meaning-making, openness to change, and psychosocial supports including mindset interventions (Bandura, 2001; Dweck, 2012; Job, Walton, Bernecker, \& Dweck, 2015; Senge, 1990, 2000; Tarter \& Hoy, 2004).

\subsubsection{Growth Mindset Interventions}

Current research is recognizing the role an organization's values play in influencing the individual beliefs and behaviors within the organization (Dweck, 2010; Tarter \& Hoy, 2004; Hoy, Tarter, \& Kottkamp, 1991). The role of a school growth mindset in educational leadership is a critical part of this body of research and growing in the literature. When faculty engaged in mindset interventions, teachers' reported increases in growth mindset beliefs, resulting in a lasting effect that influenced subsequent faculty and administrators' choices and behaviors. Growth mindset interventions included sharing information with the faculty that they can change and grow through learning and effort (Walton, 2014). When school organizations acted according to the belief that individuals could grow and learn this resulted in reduced stereotype behaviors, increased openness to new information, increased ability to resolve conflict, tolerance of others' behaviors, choices for learning goals over performance goals, persistence in the face of setbacks, resilience in the face of obstacles, and supported development of growth mindsets in their students (Blackwell, Trzesniewski, \& Dweck, 2007; Briceño, 2013; Sprengel \& Spritts, 2012; Yeager, Johnson, Spitzer, Trzesniewski, Powers, \& Dweck, 2014). Strategies promoting the development of faculty and student agency in schools were also found useful in promoting school growth mindsets (Blackwell, 2012; Farrington et al., 2012).

\subsubsection{Multicultural Mindset}

Multicultural environments are more complex social environments and require more cognitively complex thinking (King \& Shuford, 1996). The use of growth mindset interventions may be instrumental in promoting positive change toward improved multiculturalism in schools (Smith, 2015). The ability to reflect on one's thinking and behaviors and to develop a multicultural perspective requires greater cognitive development and results in increased power for caring about others who exhibit differences (Smith, Wigboldus, \& Dijksterhuis, 2008). For example, developing a shared vision of the organization that is linked to the value of increasing diversity in enrollment and retention could result in increased school outcomes. Finding realistic ways to implement change, providing research-based evidence that challenge assumptions, sound reasons for new practices, emphasizing that hard work is a key element to good outcomes, and engaging in productive discussions is a beginning to the process (Sanders \& Sheldon, 2009). Good \& Brophy (2003) in Gay wrote, "most teachers are unaware ... of what they do while in the act of teaching" (p. 70). The success of engaging in challenging dialogues about social justice and educational equity is dependent upon educational leaders who can model openness to change and provide skilled facilitation of challenging faculty dialogues. Training faculty using growth mindset interventions may increase readiness for school change initiatives through priming the belief that individuals can grow and learn (Heslin \& VandeWalle, 2011; Keevers \& Treleaven, 2011). 


\subsection{Organizational Learning Variables}

The following section describes selected variables for testing in this study drawn from the literature on organizational learning theory and included in engaging school structures of the Open Systems model. Malleable variables shown to be correlated with, and to explain, positive school outcomes included; principal openness to change, faculty openness to change, and work locus of control.

\subsubsection{Openness to Change}

Klecker and Loadman (1999) reported on a large scale study performed during a restructuring of 306 schools in an eastern state using the Inventory of Change in Organizational Culture to measure principal openness to change on three dimensions; affective, cognitive, and behavioral. The restructuring was to move schools away from an embedded hierarchal design of control and compliance to one of "interconnectedness, active learning, shared decision making, professional development for the staff, and higher levels of thinking and achievement for all students" as recommended in Fullan's (1993) work on organizational change. Results revealed a negative correlation between how principals thought about the change and how they reported they felt toward the change. Overall principals reported they held positive thoughts about the change and a willingness to promote it to the faculty, acted to facilitate the change slightly less than they reported, but experienced negative feelings toward the change.

Principals have become the change agents in schools leading faculty to adapt and accept changes that may be initiated from outside the organization. Implications from the study suggest principals need concrete information that the change will produce positive outcomes for students in order for them to embrace change in their schools (Aslan, Beycioglu, \& Konan, 2008). A second study produced similar results in the three dimensions measured (Huang, 1993). Other studies suggested a principals positive attitudes towards change, openness to new ways of doing, and recognition of the potential benefits from change resulted in increased effectiveness. Faculty perceptions of principal openness to change were positively and significantly correlated with faculty openness to change (Cagle, 2012). Research suggested it would be useful to train administrators to reflect on and evaluate their own growth mindset and diversity beliefs.

Mindset interventions have been used in schools and shown to correlate with openness to new learning and a belief in the faculty's ability to help all students grow and learn (Dweck, 2012; Dai \& Cromley, 2014; Walton, 2014). Having a growth mindset culture may contribute to factors supporting the development of culturally responsive teaching in schools, culturally responsive organizational learning, and increased multicultural organizational efficacy resulting in improved school outcomes (Goddard, Hoy, \& Woolfolk, 2000).

\subsubsection{Work Locus of Control}

Work locus of control is domain specific and is comprised of variables from one's work environment such as performance, satisfaction, behavior, and organizational commitment (Spector, 1988; Wang et al., 2010, p. 762). Bandura (2001) described the individual's need to 
gain control over his environment through predictability and by exercising personal choice (Plaks, Grant, \& Dweck, 2005). Locus of control was also shown as a foundational factor in improved student outcomes and increased school efficiency (Farrington et al., 2012). Tarter and Hoy's (2004) research revealed a positive relationship between personal control over one's work and school effectiveness. An individual's Wloc of control is influenced by one's interpersonal skills. Strong interpersonal skills resulted in better relationships with their supervisors and co-workers and the belief the individual could influence the others' behavior in a favorable way; resulting in the belief they had higher internal control in the work place. This resulted in an increase in work locus of control (Furnham \& Drakeley, 1993). Similarly, learner agency was an important factor in the development of meaningful learning (Novak, 2002, 2011). Persistence, motivation, and effort toward goal attainment increased with an increase in the individual's perception that one's effort would produce the desired outcome.

Figure 1 shows a model of the hypothesized relationship between the independent variables selected from the literature for testing and the dependent variable of a school's growth mindset.

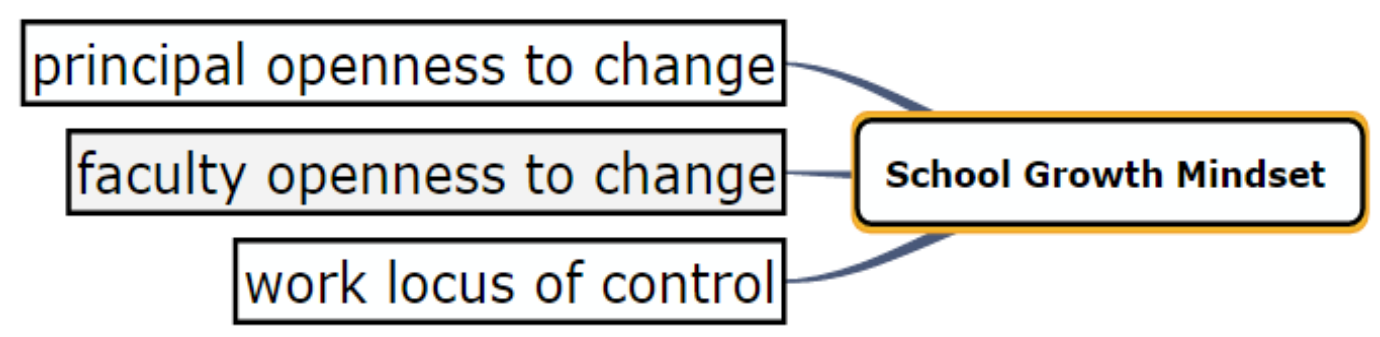

Figure 1. Model of hypothesized relationship between organizational learning variables (independent variables) and a school growth mindset culture (dependent variable)

\section{Research Design and Methods}

This exploratory study used a quantitative research design and SPSS analytical software to investigate the relationship between a small group of teachers $(n=64)$ and administrators' $(n$ $=5$ ) perceptions of their school principal's openness to change, faculty openness to change, individual work locus of control, and their school's growth mindset. Data collection took place at four middle and high schools, in a mostly rural northwestern state, during the months of October and November 2014, and included the use of paper and pencil Likert-style surveys delivered on-site at school staff meetings. Surveys included the 8-item Work Locus of Control short form that captured job-related variables such as performance, satisfaction, behavior, and organizational commitment (Spector, 1988); the 19-item Faculty Change Orientation Scale (FCOS) that measured three subscales quantifying variables in the domains of administrator and faculty openness to change and community press (Hoy, 2014); a 19-item What's My School Mindset Survey that quantifies a school mindset culture (Blackwell, 2012); and a demographic questionnaire. Data analyses were performed to determine covariance and 
correlations with an analysis of variance. Methods used included: cross tabs to explore potential influences of the demographic data on the dependent variable; a correlation analysis of variables; and a multiple regression analysis of significantly correlated variables. The main research question addressed in this project was, "Is there a relationship between principal openness to change, faculty openness to change, work locus of control, and school growth mindset?"

\subsection{Participants}

The participants for this study included a convenience sample of four middle and high schools out of a total 416 middle and high schools in the subject state. The subject schools were accessible to the researcher from public school administrators she knew. Two schools had student populations in the range $150 \leq 300$ and two schools had student populations ranging between $300 \leq 500$. Seventy-one questionnaires were distributed to teachers and six to administrators. The response rate was $94 \%$ for teacher surveys $(n=64)$ and $80 \%$ for Administrators $(n=5)$. The only significant difference in participant characteristics was for gender at the middle school level where one middle school had an all-female teaching faculty. All participants were from rural school locations. The average number of total years teaching by teachers was 4.0 years, $42 \%$ of the teachers surveyed were male and $58 \%$ were female. The education level of the participants was 36\% Master's degree, $62 \%$ bachelor's degree, and $2.0 \%$ doctoral education level. The total number of teachers surveyed represents less than one percent of teachers in the state of Montana. One of the respondents completed the mindset surveys but not the FOC and Wloc surveys and the responses were not included in the correlation and regression calculations.

\subsection{Procedures and Data Collection}

Data collection took place during the months of October and November 2014 and included participant responses to paper and pencil Likert style surveys provided in regular faculty meetings or distributed to teachers to respond individually. The administrators of two schools distributed the surveys to their teachers and this researcher drove to the other two schools to distribute and collect the surveys. Standardized instructions were provided to the survey administrators and the participants were informed of the voluntary nature of participation and that they could stop at any time, or not answer any questions they chose. Participants were also informed their responses would be confidential. Signed consent forms were collected separately from the completed surveys to ensure confidentiality. The average time to complete the surveys was from 5 to 15 minutes. Each survey was numbered and coded. The survey included 99 Likert scale questions and 10 demographic questions. Because the survey was long it was anticipated there would be a lower than usual response rate. However, all but four participants completed the surveys. One paraprofessional began to complete the survey; a teacher chose not to complete significant portions of the survey; an absent school administrator did not return the survey by mail, and one teacher chose not to complete the individual survey. 


\subsection{Instruments and Measures}

A combined survey instrument, composed of seven separate validated and reliable survey questionnaires and a demographic questionnaire, was used to collect data for this study. The questionnaires relevant to this study included, the What's My School Mindset (Mindset Works, Inc., 2015a-2015c); the Change Orientation Scale (FCOS), (Hoy, 2015); the Work Locus of Control Scale (Wloc), (Spector, 1988) and a demographic survey. The instruments are described below.

\subsubsection{What's My School Mindset Survey (WMSM)}

The 19-item, Likert-style WMSM scale collected respondents level of agreement to statements from $1=$ Strongly Disagree to $6=$ Strongly Agree. This survey was used to measure the extent to which teachers believed faculty in their school saw "themselves as learners and where they support one another in developing toward individual and common goals." The WMSM survey measured the level of teacher participation in leadership and decision-making, openness to feedback, accepting change as a normal condition of the school, sharing knowledge, continuous improvement, communities of practice, beneficial professional development, students' needs met or working to identify ways to meet them, and a school-wide pride (Blackwell, 2012). The higher the mean score on the survey the more the respondent saw the school as demonstrating the characteristics of a growth mindset culture. Results from the analyses using the data collected on the What's My School Mindset scale for this study were analyzed for reliability and showed a Cronbach's alpha of .92 for 19 items. The mean response for the 19-item WMSM scale was 3.80 with an overall standard deviation of .73. Appendix 1 includes the What's My School Mindset survey items.

\subsubsection{The Change Orientation Scale (COS)}

The COS was used to determine the extent to which individual respondents saw their principal and faculty open to school change and their community pressing for school change and improvement (Hoy, 2015). The instrument included 19-items and measured participant level of agreement to survey statements on a scale of 1-6 from Strongly Disagree to Strongly Agree. Examples of survey questions included are, "In this school, faculty welcomes change," and "In this school, the principal balks at new suggestions."

Three subscales collected quantified variables in the domains of faculty openness to change ( 9 items), principal openness to change ( 6 items), and community press for change (4 items). The alpha coefficients for the subscales were: faculty openness to change (.95), principal openness to change (.87), and community press for change (.87). Community press for change was not selected for testing in this study since the literature revealed no significant influence from this factor on school outcomes (Tarter \& Hoy, 2004). A variety of factor and predictive studies have used the Change Orientation Scale survey and demonstrated validity for the item constructs (Kearney \& Smith, 2008). Reliability statistics for this scale were evaluated using the data from this study and showed a Cronbach's alpha of .864 for the 19 COS items. The average item rating across the 19 items was 3.63 with a standard deviation of .67 .

\subsubsection{The Work Locus of Control Survey (Wloc)}




\section{Ml Macrothink}

The Wloc is domain specific and measures the extent to which individuals believe they have control in their work place (Wang et al., 2010, p. 762). The Wloc captured job related variables such as job performance, satisfaction, behavior, and organizational commitment. The short form, used in this study, had eight items including questions such as, "On most jobs, people can pretty much accomplish whatever they set out to accomplish," or "Getting the job you want is mostly a matter of luck." Participants answered their level of agreement to statements, on a Likert-style scale from $1=$ Disagree Very Much to $6=$ Agree Very Much. A total score was calculated by summing the responses to each question. The higher the respondent's score, the higher the external locus of control.

External locus of control was considered less favorable and suggested the individual felt their work environment was influenced more by others than by their own efforts. The internal consistency (coefficient alpha) for Anglo countries (Australia, Canada, New Zealand, UK, US) was .81 for the 8 -item version $(n=1170)$. A variety of studies have been performed demonstrating item construct validity for Wloc scale (Spector, 1988). Reliability statistics for this scale were calculated using the research data collected and showed a Cronbach's alpha of .838 for the 8 items. The overall mean for the eight Wloc items was 3.34 with a standard deviation of .33 .

\subsubsection{Demographic Questionnaire}

The demographic questionnaire collected participant responses to questions on school size, position, length of participant's tenure at the school, grade levels they taught, education level, gender, whether their school was involved in a change process, what level of implementation they were in, and the percentage of free and reduced lunch population at the school. Items were a combination of multiple choice and fill-in responses.

\section{Results}

The research data were explored using correlational analysis to answer the overarching question, "Is there a relationship between principal openness to change, faculty openness to change, work locus of control and school Mindset?" A null hypothesis was proposed.

Hypothsis $_{0}=$ There is no relationship between principal and faculty perceptions of openness to change, internal work locus of control, and school growth mindset.

\subsection{Correlation Analysis}

Results from the correlational analysis found that principal openness to change, faculty openness to change and school growth mindset were significantly related $(p<.001)$. Work locus of control was negatively correlated and this was considered favorable because the higher the value of the Wloc measures the higher the external locus of control. These results suggest that faculty openness to change, principal openness to change, and work locus of control had small to moderate significant correlations with growth school mindset.

The null hypothesis was rejected based upon correlation analyses that provided percentages showing significant relationships in each variable's mean scores. Table 1 summarizes the means and standard deviations. Table 2 shows the results of a correlation analysis. 
Table 1. Means and standard deviations

\begin{tabular}{|l|l|l|l|}
\hline Variables & Mean & SD & N \\
\hline Principal Openness to Change (POC) & 4.4804 & .842 & 68 \\
\hline Faculty Openness to Change (FOC) & 3.3791 & .872 & 68 \\
\hline Work Locus of Control (Wloc) & 18.750 & 5.138 & 68 \\
\hline SM & 3.782 & .741 & 68 \\
\hline
\end{tabular}

Table 2. Correlations of variables

\begin{tabular}{|l|l|l|l|}
\hline Variables & FOC (IV) & Wloc (IV) & SM (DV) \\
\hline Principal Openness to Change (POC) & $.376^{*}$ & $-.433^{*}$ & $.654^{*}$ \\
\hline Faculty Openness to Change (FOC) & & $-.240^{* *}$ & $.572^{*}$ \\
\hline Work Locus of Control (Wloc) & & & $-.570^{*}$ \\
\hline
\end{tabular}

Note. **variable with $p<.05 ; *$ variable with $p \leq .001$.

\subsection{Multiple Regression Analysis}

A multiple regression was conducted to investigate the relationship between the independent variables principal openness to change, faculty openness to change, individual work locus of control, and the dependent variable school growth mindset. Preliminary analyses were performed to ensure that the data met the assumptions of normality, linearity, multi-collinearity and homoscedasticity required for multiple regression analysis. All three independent variables where entered simultaneously into the regression analysis.

The results from the multiple regression analysis revealed faculty openness to change, principal openness to change, and work locus of control explained a significant proportion $\left(R^{2}=.617\right)$ of the variance in teacher mindset scores $\left(F_{(3,68)}=36.975, p<.001\right)$. The $R^{2}$ of .617 is not only significant but is also considered a large effect (Cohen, 1988). The strongest predictor was principal openness to change $(\beta=.383)$, followed by faculty openness to change $(\beta=.352)$, and work locus of control $(\beta=-.320)$. Table 3 shows $\beta$ and $p$ values for the three independent variables. Figure 2 shows a model of the results of the regression of the independent variables on the dependent variable of school growth mindset mean score. 
Table 3. Regression on independent variables and school mindset

\begin{tabular}{|l|l|l|l|}
\hline Variables & $B$ & $\beta$ & $p$ \\
\hline Principal Openness to Change (POC) & .337 & .383 & $<.001$ \\
\hline Faculty Openness to Change (FOC) & .299 & .352 & $<.001$ \\
\hline Work Locus of Control (Wloc) & -.046 & -.320 & $<.001$ \\
\hline
\end{tabular}

Note. $R=.796$ and adjusted $R^{2}=.617^{*}, d f=3, n=68, F=36.975$.

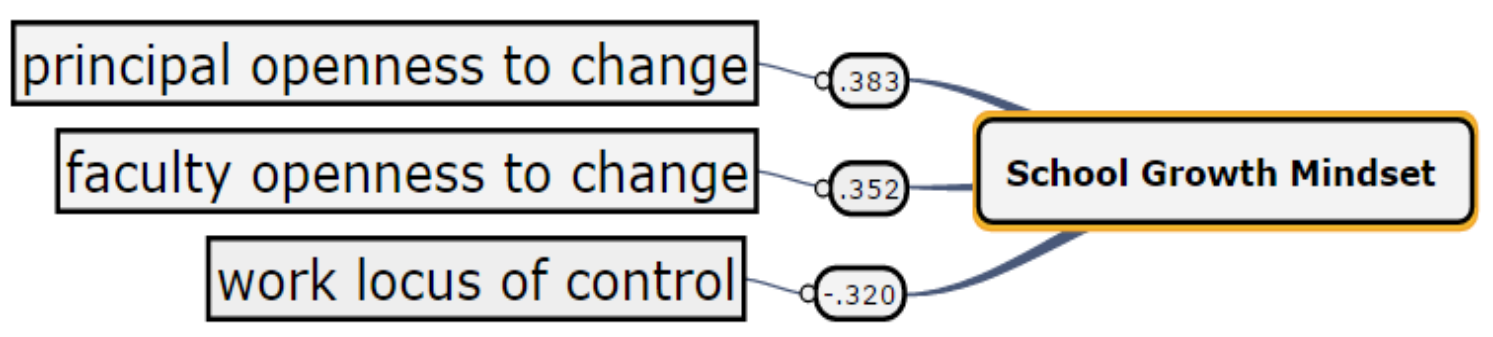

Figure 2. Model of results of regression analyses of independent variables on dependent variable school growth mindset (mean score) showing $\beta$ scores

\subsection{Summary of Results}

In sum, correlation analysis of the data indicated small to moderate significant relationships between the independent variables of principal openness to change, faculty openness to change, work locus of control, and the dependent variable of school growth mindset, confirming the alternative hypothesis $\left(\mathrm{H}_{\mathrm{a}}\right)$. The multiple regression analysis revealed the independent variables explained significant amount of the variability in school growth mindset mean. As predicted, the hypothesis that the variables would explain significant variation in school growth mindset was supported. Principal openness to change explained the most variability in school growth mindset, with faculty openness to change following, and finally, work locus of control third.

\section{Conclusions and Recommendations}

School faculty are increasingly challenged to use cognitively complex reflexive thinking, to be open to differences, and to use reflection and action as the basis for change that "facilitates social justice in a multicultural, democratic society" (Thornton \& McEntee, 1995, p. 254; King \& Kitchener, 1994; King \& Shuford, 1996). Further, as school environments become increasingly multicultural, teachers have an increasing responsibility to develop and demonstrate culturally caring educational behaviors. Administrators have the responsibility to develop faculty responsiveness to student diversity and to adapt to a continually changing and 
increasingly complex school environment. School leaders must consider faculty perceptions, explore their openness to change, and gather data on faculty's beliefs about whether their school works together to help all students learn and grow. This study provides further empirical evidence of the usefulness of the WMSM scale for exploring a faculty's beliefs about their school culture.

The results of this study provided empirical evidence that there is a relationship between school growth mindset and organizational literature variables shown to explain positive school improvement; consistent with the literature showing teacher perceptions of their faculty's openness to change, their principal's openness to change, and work locus control correlated with organizational climate and culture (Tarter \& Hoy, 2004). These findings are consistent with the concept of a collaborative school climate concept where principal and faculty have developed positive relationships, good communication, and cooperate in decision-making resulting in increased sense of control over their work environment (Spector, 1998; Dweck, 2012).

With the principal as the primary agent modeling a change orientation, this research revealed that the faculty's perception of their principal's behaviors of openness to change could influence the faculty toward increased openness to change. Challenging assumptions is the first step in developing new learning. Further, principals can "mediate faculty uncertainties" through using reflective practices and development of their own growth mindset beliefs (Dweck, 2012; Kearney, 2007, p. 102). Changes can occur in a school through encouragement and support, opening opportunities for faculty engagement in the decision making and change process, alignment of personal and organizational goals, and increasing faculty perceptions of their level of work locus of control. The WMSM scale can be used to provide reliable data to begin dialogues that can lead to development of a school environment that is supportive of a multicultural lens and increased educational equity.

\subsection{Limitations}

The convenience sample limited the size of the subject pool and the number of participants available. However, the use of multiple surveys and abundance of data points collected attempted to increase the reliability and the large effect size selected allowed for a small subject sample size. The researchers did not validate by observation the individual self-reports of participants on the surveys and this could be a potential future study. Participants were drawn from a largely rural population, small school sizes, and a uniform demographic. This limits the generalizability of the results to diverse populations. However, the results of the study were consistent with the literature and with the results of other studies that included varied demographics.

\subsection{Recommendations for Future Studies}

Future studies could include qualitative studies to determine more of the epistemological factors that influence the individual's perceptions and orientations to openness to change and growth mindset. Finally, a quantitative study identifying organizational factors included in school mindset with school outcomes is a rich area for study and could contribute to the body 
of research literature providing empirical evidence of psychosocial factors contributing to improved school outcomes.

\section{References}

Argyris, C., \& Schon, D. (1996). Organizational Learning II: Theory, method and practice. Addison Wesley Publishing, Reading, Massachusetts.

Aslan, M., Beycioglu, K., \& Konan, N. (2008). Principals' Openness to Change in Malatya, Turkey. International Electronic Journal for Leadership in Learning, 12(8), 8. Retrieved from http://files.eric.ed.gov/fulltext/EJ940565.pdf

Bandura, A. (2001). Social cognitive theory: An agentic perspective. Annual Review of Psychology, 52, 1-26. http://dx.doi.org/10.1146/annurev.psych.52.1.1

Baumeister, R., Masicampo, E., \& Vohs, K. (2011). Do conscious thoughts cause behavior? Annu. Rev. Psychol., 62(1), 331-361. http://dx.doi.org/10.1146/annurev.psych.093008.131126

Blackwell, L. (March 28, 2012). Developing a growth mindset school culture. Mindset Works' Blog: Cultivating Growth Mindsets. Retrieved October 26, 2016, from http://blog.mindset works.com/blog-page/home-blogs/entry/developing-a-growth-mindset-school-culture-2-ar

Blackwell, L. S., Trzesniewski, K. H., \& Dweck, C. S. (2007). Implicit theories of intelligence predict achievement across an adolescent transition: A longitudinal study and an intervention. Child Development, 78(Study 1), 246-263. http://dx.doi.org/10.1111/j.1467-862 4.2007.00995.x

Briceño, E. (July 28, 2014). Mindsets and student agency. Competency Works. Retrieved from http://www.competencyworks.org/analysis/mindsets-and-student-agency/

Burnette, J. L., O’Boyle, E. H., VanEpps, E. M., Pollack, J. M., \& Finkel, E. J. (2013). Mind-sets matter: A meta-analytic review of implicit theories and self-regulation. Psychological Bulletin, 139(3), 655-701. http://dx.doi.org/10.1037/a0029531

Burnette, J., \& Pollack, J. (2013). Implicit theories of work and job fit: Implications for job and life satisfaction. Basic and Applied Social Psychology, 35(4), 360-372. http://dx.doi.org/ 10.1080/01973533.2013.803964

Cagle, K. E. (2012). Faculty perceptions of principal support and change orientation in Virginia high schools (Order No. 3514838). ProQuest Dissertations \& Theses Global.

Cohen, J. (1988). Statistical power analysis for the behavioral sciences (2nd ed.). Hillsdale, NJ: Erlbaum.

Dai, T., \& Cromley, J. G. (2014). Changes in implicit theories of ability in biology and dropout from STEM majors: A latent growth curve approach. Contemporary Educational Psychology, 39(3), 233-247. http://dx.doi.org/10.1016/j.cedpsych.2014.06.003

Dweck, C. (1986). Motivational processes affecting learning. American Psychologist, 41(10), 1040-1048. http://dx.doi.org/10.1037/0003-066X.41.10.1040 


\section{MInstitute Macrothink $_{\text {Int }}$}

Dweck, C. S. (2008). Mindsets and math/science achievement. Prepared for the Carnegie Corporation of New York-Institute for Advanced Study Commission on Mathematics and Science Education. Retrieved October 25, 2016, from http:/www.growthmindsetmaths.com/ uploads/2/3/7/7/23776169/mindset_and_math_science_achievement_-_nov_2013.pdf

Dweck, C. S. (2010). Mind-sets and equitable education. Principal Leadership, 26-29. Retrieved October 25, 2016, from http://www.oakton.edu/user/0/bcrocket/Old\%20files. English\%20101/Dweck.intelligence.pdf

Dweck, C. S. (2012). Mindsets and human nature: Promoting change in the Middle East, the schoolyard, the racial divide, and willpower. American Psychologist, 67(8), 614-622. http://dx.doi.org/10.1037/a0029783

Farrington, C. A., Roderick, M., Allensworth, E., Nagaoka, J., Seneca-Keyes, T. S., Johnson, D. W., \& Beechum, N. O. (2012). The role of noncognitive factors in shaping school performance: A critical literature review. Teaching adolescents to become learners. Chicago: University of Chicago Consortium on Chicago School Research. Retrieved October 25, 2016, from https://consortium.uchicago.edu/sites/default/files/publications/Noncognitive\%20Report. pdf

Fullan, M. (1993). Change forces: Probing the depths of educational reform (Vol. 10). Psychology Press. Retrieved October 25, 2016, from http://files.eric.ed.gov/fulltext/ ED373391.pdf

Furnham, A., \& Drakeley, R. (1993). Work locus of control and perceived organizational climate. European Work and Organizational Psychologist, 3(1), 1-9. http://dx.doi.org/ $10.1080 / 09602009308408572$

Gay, G. (2010). Culturally responsive teaching theory, research, and practice. New York, NY: Teachers College Press.

Goddard, R. D. (2002). A theoretical and empirical analysis of the measurement of collective efficacy: The development of a short form. Educational and Psychological Measurement, 93, 467-476. http://dx.doi.org/10.1177/0013164402062001007

Goddard, R. D., Hoy, W. K., \& Woolfolk, A. (2000). Collective teacher efficacy: Its meaning, measure, and effect on student achievement. American Education Research Journal, 37(2), 479-507. http://dx.doi.org/10.3102/00028312037002479

Good, C., Rattan, A., \& Dweck, C. S. (2012). Why do women opt out? Sense of belonging and women's representation in mathematics. Journal of Personality and Social Psychology, 102(4), 700-717. http://dx.doi.org/10.1037/a0026659

Hanson, J. L. (2015). Determination and validation of the "What's My School Mindset?" instrument factor structure (Order No. 3722197). Dissertations \& Theses at Montana State University; ProQuest Dissertations \& Theses Global.

Hanson, J., Bangert, A., \& Ruff, W. (2016). A validation study of the What's My School Mindset? survey. Journal of Educational Issues, 2(2), 244-266. http://dx.doi.org/10.5296/ 
jei.v2i2.10138

Heslin, P. A., \& Vande Walle, D. (2011). Performance appraisal procedural justice: The role of a manager's implicit person theory. Journal of Management, 37(6), 1694-1718. http://dx.doi.org/10.1177/0149206309342895

Hong, Y. Y., Benet-Martinez, V., Chiu, C. Y., \& Morris, M. W. (2003). Boundaries of cultural influence construct activation as a mechanism for cultural differences in social perception. Journal of Cross-Cultural Psychology, 34(4), 453-464. http://dx.doi.org/10.1177/0022022103 034004005

Hong, Y. Y., Morris, M. W., Chiu, C. Y., \& Benet-Martinez, V. (2000). Multicultural minds: A dynamic constructivist approach to culture and cognition. American Psychologist, 55(7), 709. http://dx.doi.org/10.1037/0003-066X.55.7.709

Hoy, W. K. (2015). Wayne K. Hoy Professor Emeritus. Website. Retrieved October 25, 2016, from http://www.waynekhoy.com/power_points.html

Hoy, W. K., \& Sweetland, S. R. (2001). Designing better schools: The meaning and measure of enabling school structures. Educational Administration Quarterly, 37(3), 296-321. http://dx.doi.org/10.1177/00131610121969334

Hoy, W., Tarter, C., \& Kottkamp, B. (1991). Open schools/healthy schools measuring organizational climate. Newbury Park: Sage Publications.

Huang, T. (1993). The relationships between elementary school principals'psychological types and openness to selected changes in organizational culture (Order No. 9325513). ProQuest Dissertations \& Theses Global. Retrieved October 25, 2016, from http://digitalcommons. liberty.edu/cgi/viewcontent.cgi?article=2097\&context=doctoral

Job, V., Walton, G. M., Bernecker, K., \& Dweck, C. S. (2015). Implicit theories about willpower predict self-regulation and grades in everyday life. Journal of Personality and Social Psychology, 108(4), 637-647. http://dx.doi.org/10.1037/pspp0000014

Kang, S., Scharmann, L. C., \& Noh, T. (2004). Reexamining the role of cognitive conflict in science concept learning. Research in Science Education, 34(1), 71-96. http://dx.doi.org/ 10.1023/B:RISE.0000021001.77568.b3

Kearney, S. (2007). Principal Influence: A Study of Its Effect on School Change. The University of Texas at San Antonio: ProQuest.

Kearney, S., \& Smith P. A. (2008). A theoretical and empirical analysis of change orientations in schools. In W. K. Hoy \& M. DiPaola (Eds.), Studies in School Improvement. Greenwich, CN: Information Age.

Keevers, L., \& Treleaven, L. (2011). Organizing practices of reflection: A practice-based study. Management Learning, 42(5), 505-520. http://dx.doi.org/10.1177/1350507610391592

King, P., \& Kitchener, K. (1994). Developing reflective judgment: Understanding and promoting intellectual growth and critical thinking in adolescents and adults. San Francisco: 
Jossey-Bass.

King, P., \& Shuford, B. (1996). A multicultural view is a more cognitively complex view: Cognitive development and multicultural education. American Behavioral Scientist, 40(2), 153-164. http://dx.doi.org/10.1177/0002764296040002006

Klecker, B. M., \& Loadman, W. E. (1999). Measuring principals' openness to change on three dimensions: Affective, cognitive and behavioral. Journal of Instructional Psychology, 26(4), 213. Retrieved October 26, 2016, from http://www.freepatentsonline.com/article/JournalInstructional-Psychology/62980770.html

Mangels, J. A., Good, C., Whiteman, R. C., Maniscalco, B., \& Dweck, C. S. (2012). Emotion blocks the path to learning under stereotype threat. Social Cognitive and Affective Neuroscience, 7(2), 230-41. http://dx.doi.org/10.1093/scan/nsq100

Martin, J. (1979). Self-regulated learning, social cognitive theory, and agency. Educational Psychologist, 39(2), 135-145. http://dx.doi.org/10.1207/s15326985ep3902_4

Mindset Works, Inc. (2015a). About mindset works. Retrieved April 14, 2015, from http://www.mindsetworks.com/webnav/about.aspx

Mindset Works, Inc. (2015b). Dr. Dweck's discovery of fixed and growth mindsets have shaped our understanding of learning. Retrieved October 26, 2016, from http://www.mindsetworks. com/webnav/whatismindset.aspx

Mindset Works, Inc. (2015c). What's My School Mindset? (Para. 5). Retrieved October 26, 2016, from https://www.mindsetworks.com/assess/

Negari, G. M., \& Donyadary, M. (2013). The relationship between self-efficacy and autonomous learning. Journal of Academic and Applied Studies (Special Issue on Applied Sciences), 3(12), 14-22. Retrieved October 25, 2016, from http://www.academians.org/Media/ Default/Articles/December2013/December2013-2.pdf

Nisbett, R., \& Miyamoto, Y. (2005). The influence of culture: Holistic versus analytic perception. Trends in Cognitive Sciences, 9(10), 467-473. http://dx.doi.org/10.1016/j.tics.2005. 08.004

Novak, J. (2002). Meaningful learning: The essential factor for conceptual change in limited or inappropriate propositional hierarchies leading to empowerment of learners. Science Education, 86(4), 548-571. http://dx.doi.org/10.1002/sce.10032

Novak, J. (2011). A theory of education: Meaningful learning underlies the constructive integration of thinking, feeling, and acting leading to empowerment for commitment and responsibility. Meaningful Learning Review, 1(2), 1-14. Retrieved October 25, 2016, from http://www.if.ufrgs.br/asr/artigos/Artigo_ID7/v1_n2_a2011.pdf

Novak, J., \& Gowin, D. (1984). Learning how to learn. Cambridge, Cambridgeshire: Cambridge University Press. http://dx.doi.org/10.1017/CBO9781139173469

Plaks, J. E., Grant, H., \& Dweck, C. S. (2005). Violations of implicit theories and the sense of 
prediction and control: Implications for motivated person perception. Journal of Personality and Social Psychology, 88(2), 245-262. http://dx.doi.org/10.1037/0022-3514.88.2.245

Ponton, M., \& Rhea, N. (2006). Autonomous Learning from a Social Cognitive Perspective. New Horizons in Adult Education and Human Resource Development, 20(2), 38-49. http://dx.doi.org/10.1002/nha3.10250

Rottschaefer, W., \& Knowlton, W. (1979). A cognitive social learning theory perspective on human freedom. Behaviorism, 7(1), 17-22. Retrieved October 25, 2016, from http://www.jstor.org/stable/27758927

Ruedy, N., \& Schweitzer, M. (2011). In the moment: The effect of mindfulness on ethical decision making. Journal of Business Ethics, 95, 73-87. http://dx.doi.org/10.1007/s10551 $-011-0796-\mathrm{y}$

Ruff, W. (2002). Constructing the role of instructional leader: The mental models of urban elementary school principals (Doctoral dissertation). The University of Texas at San Antonio.

Sanders, M., \& Sheldon, S. (2009). Principals matter: A guide to school, family, and community partnerships. Thousand Oaks, Calif.: Corwin.

Schunk, D. (2012). Learning theories: An educational perspective. Boston, MA: Pearson.

Senge, P. (2000). Schools that learn: A fifth discipline fieldbook for educators, parents, and everyone who cares about education. New York, NY: Doubleday.

Senge, P. M. (1990, revised 2006). The fifth discipline: The art \& practice of the learning organization. New York, NY: Doubleday.

Smith, D. (2015). Diversity's Promise for Higher Education: Making It Work. Baltimore, MD: Johns Hopkins University Press.

Smith, P. A., \& Hoy, W. K. (2005). FCOS. Retrieved October 25, 2016, from http://www.waynekhoy.com/pdfs/change_scale.pdf

Smith, P. K., Wigboldus, D. H. J., \& Dijksterhuis, A. (2008). Abstract thinking increases one's sense of power. Journal of Experimental Social Psychology, 44(2), 378-385. http://dx.doi.org/ 10.1016/j.jesp.2006.12.005

Spector, P. E. (1988). Development of the work locus of control scale. Journal of Occupational Psychology, 61(4), 335-340. http://dx.doi.org/10.1111/j.2044-8325.1988.tb00470.x

Sprengel, M., \& Spritts, M. (2012). OA13.02. Utilizing mind-body practices in public schools: teaching self-regulation skills and fostering resilience in our next generation. $B M C$ Complementary and Alternative Medicine, 12(Suppl 1), O50. http://dx.doi.org/10.1186/ 1472-6882-12-S1-O50

Tarter, C., \& Hoy, W. (2004). A systems approach to quality in elementary schools: A theoretical and empirical analysis. Journal of Educational Administration, 42(5), 539-554. http://dx.doi.org/10.1108/09578230410554052 


\section{Macrothink}

Vygotsky, L. S. (1962). Thought and language. Cambridge, Massachusetts: Institute of Technology: M.I.T. Press. http://dx.doi.org/10.1037/11193-000

Vygotsky, L. S. (1978). Mind in society: The development of higher psychological processes. Cambridge, MA: Harvard University Press.

Wagner, T., \& Kegan, R. (2006). Change leadership: A practical guide to transforming our schools. San Francisco, Jossey.

Walker-Dalhouse, D., \& Dalhouse, A. (2006). Investigating white preservice teachers' beliefs about teaching in culturally diverse classrooms. The Negro Educational Review, 57(1-2), 69-84. Retrieved October 25, 2016, from http://eric.ed.gov/?id=EJ751106

Walton, G. M. (2014). The new science of wise psychological interventions. Current Directions in Psychological Science, 23(1), 73-82. http://dx.doi.org/10.1177/0963721413512856

Wang, Q., Bowling, N. A., \& Eschleman, K. J. (2010). A meta-analytic examination of work and general locus of control. Journal of Applied Psychology, 95(4), 761-768. http://dx.doi.org/ $10.1037 / \mathrm{a} 0017707$

Yeager, D. S., Johnson, R., Spitzer, B. J., Trzesniewski, K. H., Powers, J., \& Dweck, C. S. (2014). The far-reaching effects of believing people can change: Implicit theories of personality shape stress, health, and achievement during adolescence. Journal of Personality and Social Psychology, 106(6), 867-884. http://dx.doi.org/10.1037/a0036335

Zimmerman, B. J. (1989). A social cognitive view of self-regulated academic learning. Journal of Educational Psychology, 81(3), 329-339. http://dx.doi.org/10.1037/0022-0663.81.3.329

\section{Appendix}

Appendix 1. What's My School Mindset (WMSM) Survey

Scale: Never $=1$, Rarely $=2$, Sometimes $=3$, Frequently $=4$, Usually $=5$, Always $=6$

1. Leadership opportunities are open to all staff members and staff members are invited to participate periodically throughout the school year.

2. We have systems where teachers are directly involved and participate in decision-making and planning for site initiatives.

3. Administration and leaders communicate decision-making strategies with staff and elicit their input.

4. Staff are able to put ideas "on the table" and "take them off" safely during planning, collaboration, and decision-making meetings.

5. Teachers are invited to give critical feedback about administrative practices and how they would like additional support.

6. Staff members are reluctant to work with or support new or struggling teachers. 
[Reverse-scored]

7. Teachers observe one another and give each other feedback to develop the team's best practices.

8. We have exclusive cliques or "camps" within our faculty. [Reverse-scored]

9. Teachers collaborate regularly, sharing or co-developing lessons, assessments, and student work.

10. Our teachers tend to protect or guard our lessons, strategies, tests, etc. from one another. [Reverse-scored]

11. Instructional expectations, standards, and evaluation protocols are made clear to teachers in advance.

12. Administrators communicate a sincere belief that staff members can develop their teaching skills with practice and feedback.

13. Teachers receive clear feedback on and ongoing support for their practice outside of formal evaluations.

14. Teachers, coaches, and administrators work together to design goals and plans for teacher development.

15. Teachers receive professional development that is targeted to their professional needs and goals.

16. Time is provided in the work day for coaching, co-planning/co-teaching, and structured professional learning.

17. Administrators and teachers in our school truly believe that they can help all students to meet learning goals.

18. There are structures for teachers and administrators to share information and work together to meet the specific needs of individual students.

19. There is an "us against them" feeling between teachers and students. [Reverse-scored]

20. We review our current state and set improvement goals for both the short and long-term.* Copyright (C) 2011 Mindset Works, Inc. All rights reserved.

*Item 20 was excluded from this study; refer to WMSM validation study for item correlations (Hanson, Bangert, \& Ruff, 2016). 


\section{Copyright Disclaimer}

Copyright for this article is retained by the author(s), with first publication rights granted to the journal.

This is an open-access article distributed under the terms and conditions of the Creative Commons Attribution license (http://creativecommons.org/licenses/by/3.0/). 